Abstracta Iranica

Revue bibliographique pour le domaine irano-aryen

Volume 37-38-39 | 2018

Comptes rendus des publications de 2014-2016

\title{
Ergin Öpengin. The Mukri Variety of Central Kurdish. Grammar, Texts, and Lexicon
}

\section{Matteo De Chiara}

\section{(2) OpenEdition}

1 Journals

\section{Édition électronique}

URL : http://journals.openedition.org/abstractairanica/43099

DOI : 10.4000/abstractairanica.43099

ISBN : 1961-960X

ISSN : 1961-960X

Éditeur :

CNRS (UMR 7528 Mondes iraniens et indiens), Éditions de l'IFRI

Référence électronique

Matteo De Chiara, "Ergin Öpengin. The Mukri Variety of Central Kurdish. Grammar, Texts, and Lexicon », Abstracta Iranica [En ligne], Volume 37-38-39 | 2018, document 3, mis en ligne le 30 décembre 2018, consulté le 28 septembre 2020. URL : http://journals.openedition.org/abstractairanica/43099 ; DOI : https://doi.org/10.4000/abstractairanica.43099

Ce document a été généré automatiquement le 28 septembre 2020

Tous droits réservés 


\title{
Ergin Öpengin. The Mukri Variety of Central Kurdish. Grammar, Texts, and Lexicon
}

\author{
Matteo De Chiara
}

\section{RÉFÉRENCE}

Ergin Öpengin. The Mukri Variety of Central Kurdish. Grammar, Texts, and Lexicon.

Wiesbaden: Reichert, 2016, 304 p. + CD (Beiträge zur Iranistik, 40).

1 Le Mukri ou Mukriyani est une variété de kurde parlée autour de Mahabad, en Iran, très proche du kurde de Suleimaniya, mais présentant néanmoins plusieurs caractéristiques phonologiques et morphologiques. Après une introduction socio-linguistique sur le Mukri, le chapitre 2 contient "A descriptive and typologically-oriented sketch of the phonology of Mukri Kurdish" (\$2.2) et "morphology and syntax of Mukri” (\$2.3). La description s'appuie sur un corpus recueilli au Kurdistan iranien de 2009 à 2013. Deux exemples de textes avec gloses sont présentés dans le chapitre 3. La deuxième partie contient 10 textes - (disponibles en format audio sur le CD joint au volume) transcrits et traduits sur deux colonnes découpés en phrases et avec la référence de la durée des enregistrements. On peut regretter qu'il n'y ait aucune analyse détaillée des contes populaires, ce qui est cependant compréhensible, s'agissant d'un ouvrage à visée purement linguistique. En fin de volume (chapitre 5) se trouve un lexique. On ne peut que se réjouir pour cette précieuse contribution à la dialectologie du kurde. 


\section{AUTEURS}

MATTEO DE CHIARA

INALCO, Mondes iranien et indien, Paris 